\title{
MICROSTRUCTURE AND MECHANICAL PROPERTIES OF LINEAR FRICTION WELDED TITANIUM SUBJECTED TO ECAP
}

\author{
A.P. Zhilyaev1,2, R.M. Kashaev,3, A.M. Khusnullin², G.I. Raab',3, J. Calvo ${ }^{4}$ \\ and J.M. Cabrera ${ }^{4}$ \\ ${ }^{1}$ Nosov Magnitogorsk State Technical University, Magnitogorsk, 455000 Russia \\ ${ }^{2}$ Institute for Metals Superplasticity Problems, RAS, 39 Khalturin St., 450001, Ufa, Russia \\ ${ }^{3}$ Ufa State Aviation Technical University, 12 Karl Marx St., 450077, Ufa, Russia \\ ${ }^{4}$ Departamento de Ciencia de los Materiales e Ingeniería Metalúrgica, \\ EEBE - Universitat Politècnica de Catalunya, c/ Eduard Maristany 10-14, Barcelona, 08019 Spain
}

Received: February 19, 2018

\begin{abstract}
Commercially pure (Grade 4) titanium specimens with two types of microstructure (coarse-grained and nanostructured by means of equal channel angular pressing) were joined by linear friction welding (LFW). Microhardness measurements, tensile and compression tests as well as fracture surface inspection by scanning electron microscopy revealed similarity in tensile properties and significant discrepancy in compression behavior of two types of $\mathrm{Ti}$ specimens. Tensile test shows that fracture occurs in both cases in a region of heat affected zone. Fracture surface analysis displayed mostly ductile mode. In case of compression test coarse-grained titanium linear friction welded demonstrates a pronounced strain hardening region without fracture but nanostructured LFW titanium shows typical plastic behavior with mixing of brittle-ductile mode of rupture in the welding zone.
\end{abstract}

\section{INTRODUCTION}

Linear friction welding (LFW) is a very efficient way to join specimens using solid state diffusion process invented and industrialized by The Welding Insitute (TWI) mostly for aerospace application [1]. Schematic of the process shown in Fig. 1 suggests that it is a self-organizing process. The quality of joining depends on initial parameters of LFW such as amplitude, oscillation frequency, and an friction load applied and a post welding load [2]. The minimal power required for proper welding condition increases with frequency increase due to higher strain rate of shear deformation. In earlier reports (see for example [3]) it was established that for linear friction welding of Ti6Al4 alloy the material is expelled in a discontinuous mode, producing a series of ridges in the flash from the hottest area of the interface joined. It was also observed that the frictional heat input at the interface depends on the amplitude of oscillation.

Traditional welding of titanium alloys (arc welding) requires application of protective atmosphere during the joining process in order to avoid introducing impurities and oxidation into melted zone. Such joining are brittle in comparison with the base material due to martensitic transformation and post welding grain coarsening in heat affected zone (HAZ) [4-6]. Linear friction welding has no such drawbacks and it can be used for joining dissimilar metals including steels, aluminum, titanium and intermetallics. It can be employed for welding different components such as gear wheels, chains, hinges, wheels of turbines, electric buses, and bimetallic

Corresponding author:A.P. Zhilyaev, e-mail: alex.zhilyaev@hotmail.com 


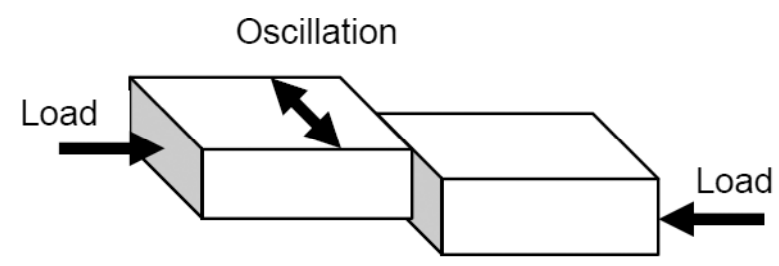

Fig. 1. Schematic of linear friction welding.

cutter blades as well as to replace damaged compressor blades [7].

In the last few years, increasing importance has been attributed to study the welded joint fracture and influence of various structural and technological factors on the fracture characteristics [8]. Investigation of the strength of welded joints is an important and urgent problem. The welded joints are traditionally tested in tension or bending. However, the characteristics obtained during such tests incompletely reflect the stress state arising during system operation. Additional data can be provided by investigations of the torsional strength of materials. Recently, a report devoted to the investigation of the mechanical properties of welded joints by the torsion method [10] revealed the weakest region of LFW rods: heat affected zone (HAZ) of base metal due to elevated temperature where significant grain growth occurs. So, it may be concluded that fracture of welded specimens is similar to the one of base metal. Compression test in many cases gives similar results. However, it is here aimed to perform compression test in order to fracture welded zone of the joint and to study the fracture surface for 2 types of commercially pure titanium: coarse grain specimens and ultra-fine grain (UFG) rods processed by means of equal channel angular pressing [11].

\section{EXPERIMENTAL METHODS AND MATERIALS}

Commercially pure titanium of nominal composition shown in Table 1 [12] was used in the current work. One set of specimens with coarse grain (CG) structure (as received) was subjected to linear friction welding operation using a laboratory scale machine (Fig. 2) [13]. The frequency of LFW was $35 \mathrm{~Hz}$, amplitude of oscillation was of about $1.3 \mathrm{~mm}$, fric-

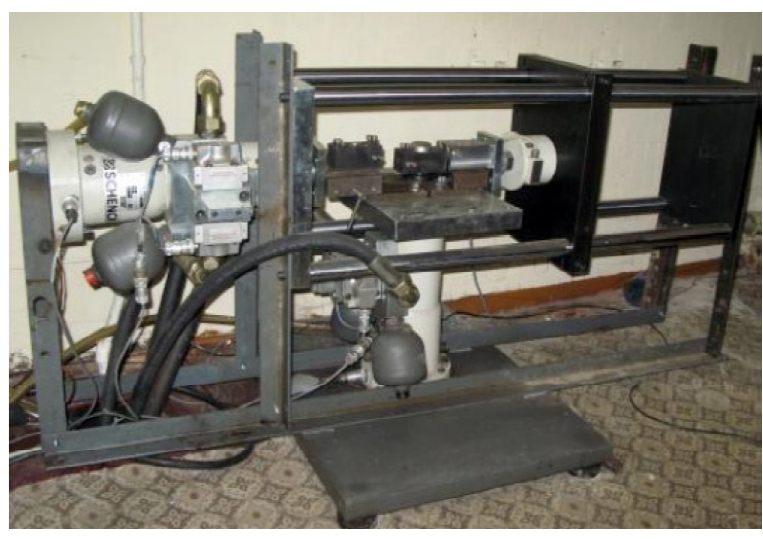

Fig. 2. Linear friction welding laboratory setup.

tion force was $1.5 \mathrm{kN}$ and forging force was $2.2 \mathrm{kN}$, welding time was $3 \mathrm{~s}$. Another set of coarse grained titanium was processed by $\operatorname{ECAP}\left(120^{\circ}\right.$, route $\mathrm{Bc}$, 4 passes, $350^{\circ} \mathrm{C}$ ) in order to achieve an ultrafinegrained structure [14]. The ECAP rods were cut into halves and were welded again using the same LFW procedure described above.

Two welded samples with CG and UFG structures were sliced for tensile testing. Dog bone miniature specimens of $4 \mathrm{~mm}$ in width, $1 \mathrm{~mm}$ in thickness and $15 \mathrm{~mm}$ in length were cut by Electric Dicharge Machine (EDM) and polished. Vickers microhardness across the welding zone was measured as well. Tensile tests were performed in a universal testing machine Instron (5982) at room temperature at initial strain rate of $1 \mathrm{~mm} / \mathrm{min}$. Another two welded samples with CG and UFG structures were machined for compression tests. Cylinders of $10 \mathrm{~mm}$ in diameter and $12 \mathrm{~mm}$ in height were tested at room temperature at an initial strain rate of 0.125 $\mathrm{mm} / \mathrm{min}$, in a similar testing machine (Instron 5585) using Teflon as a lubricant.

Structure of welding zone and fracture surfaces were acquired using a SEM Tescan VEGA.

\section{RESULTS AND DISCUSSION}

Microhardness profile: Figs. $3 a$ and $3 \mathrm{~b}$ show the microhardness profile across the welding zone for coarse grained titanium (CG + LFW) and ultrafinegrained titanium (ECAP+LFW) as a function of distance from the central line of the welding zone, cor-

Table 1. Chemical composition (wt.\%) of titanium Grade 4.

\begin{tabular}{lllllll}
\hline Titanium Grade 4 & $\mathrm{C}$ & $\mathrm{Fe}$ & $\mathrm{H}$ & $\mathrm{N}$ & $\mathrm{O}$ & $\mathrm{Ti}$ \\
\hline Nominal (max) [12] & 0.10 & 0.50 & 0.015 & 0.05 & 0.40 & Balance \\
Measured & 0.05 & 0.30 & 0.015 & 0.02 & 0.34 & Balance \\
\hline
\end{tabular}



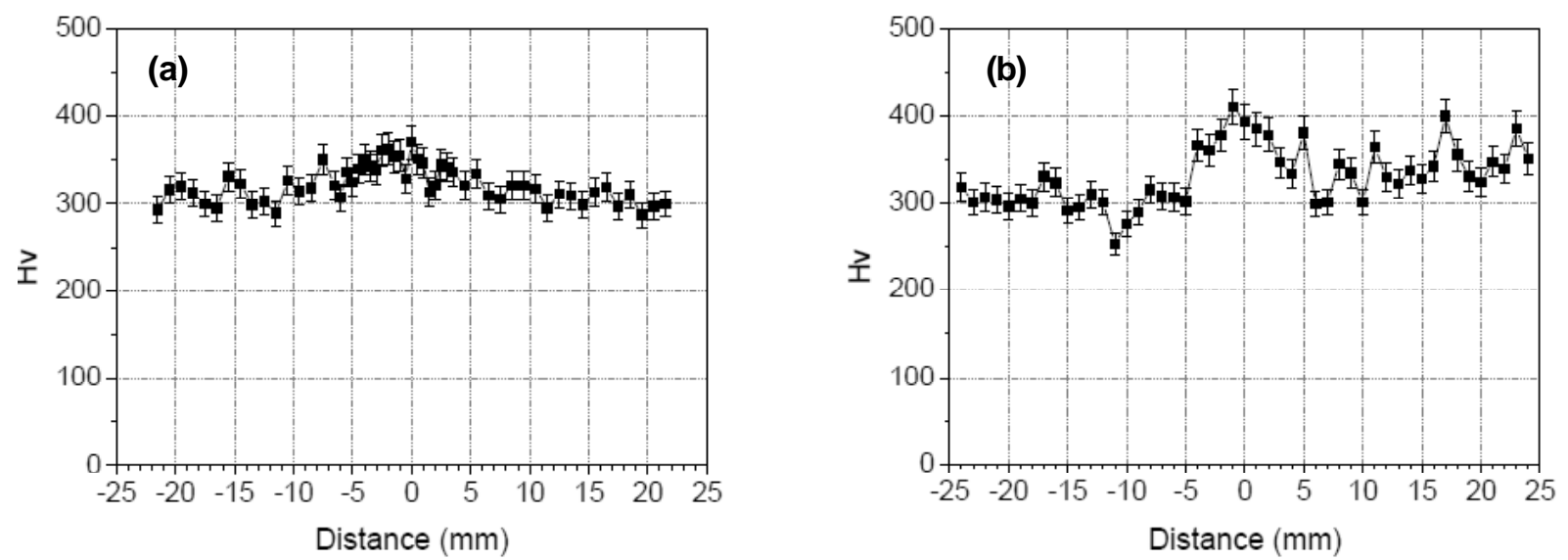

Fig. 3. Microhardness profile (HV) across the welding zone in (a) coarse-grained titanium; (b) nanostructured titanium processed by ECAP.

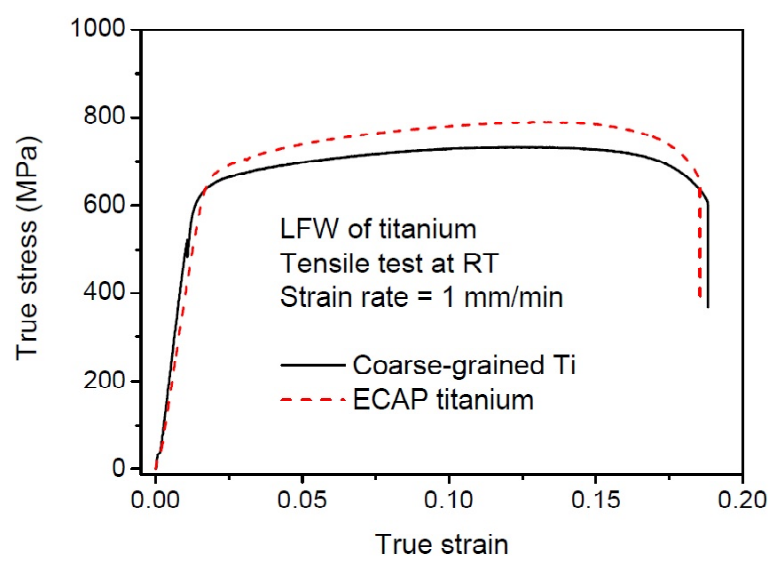

Fig. 4. True stress-strain curves of titanium LFW samples tested in tension mode.

respondingly. The ECAP+LFW sample is characterized by higher values of $\mathrm{HV}$ in the welding zone and by significant scatter in microhardness (Fig. 3b) compared to CG+LFW specimen (Fig. 3a). The maximum hardness is slightly higher in the case of ECAP+LFW samples and it reaches almost 400 $\mathrm{HV}$ at the centerline of the welding zone.

Tensile testing: Fig. 4 depicts the true strain-true stress curves for the LFW samples of coarse grained and ECAP specimens welded at the same conditions. Is it evident that both conditions (coarse and fine grained) exhibit similar tensile properties: true stress-strain curves for both conditions are identical in the range of experimental error. Both samples have fractured off the central zone which includes nugget zone and thermomechanical zone (TMAZ). Significant ductility of LFW coarse-grained and ultrafine- grained titanium samples indicates that fractures in both cases occur in the heat-affected zone (HAZ). It is characterized by almost identical microhardness values of about $300 \mathrm{MPa}$ (Fig. 3).

Microstructure: Fig. 5 depicts typical structure of welding zone of coarse-grained titanium. Low magnification view (Fig. 5a) delineates the welding zone (nugget) in range of about $100 \mu \mathrm{m}$ at the centerline. Higher magnification (Fig. 5b) displays transition zone between fine grain structure in welding zone and much coarser grains in TMAZ and HAZ areas. Fracture structure: Fig. 6 illustrates fracture surface of coarse-grained LFW titanium after tensile testing. General view of fracture surface (Fig. 6a) suggests that fracture started at upper right corner and progressed through whole cross section. It appears on fracture surface "like river flow". Higher magnification (Figs. $6 \mathrm{~b}$ and $6 \mathrm{c}$ ) reveals plastic type fracture surface with large cavities corresponding to intermetallic particles. Fig. 7 demonstrates fracture
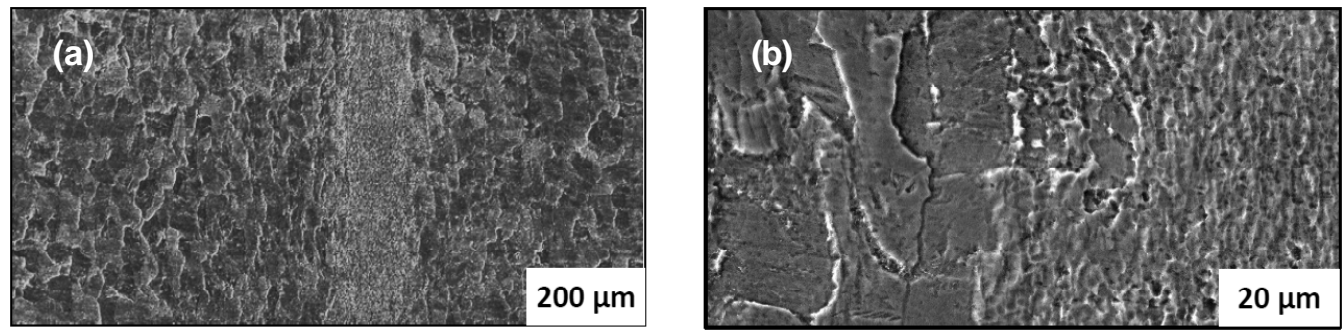

Fig. 5. SEM micrograph of welding zone of coarse-grained titanium: (a) general view; (b) details of transition area. 

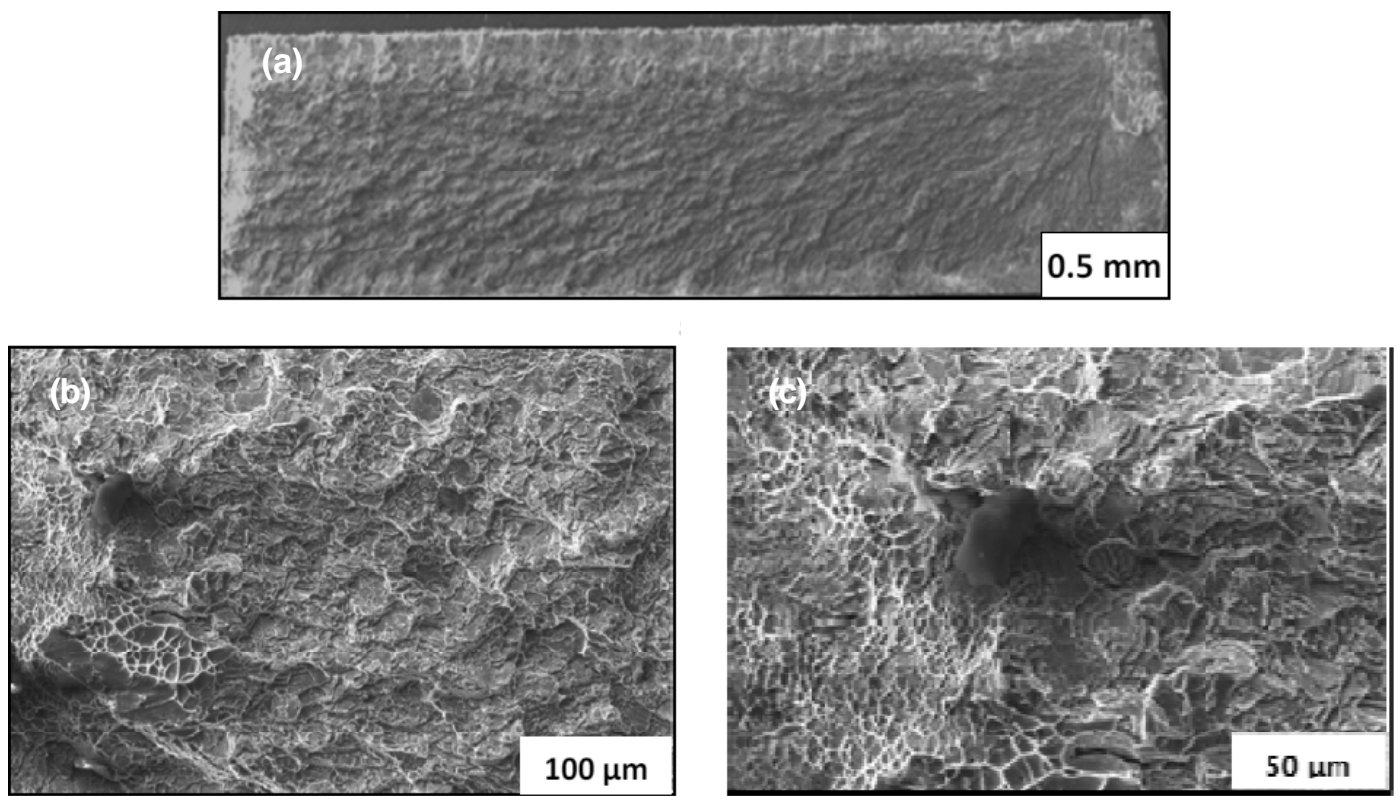

Fig. 6. General view of fractured specimen (a) and details of fractured zone for (b, c) for coarse-grained LFW titanium after tensile testing.
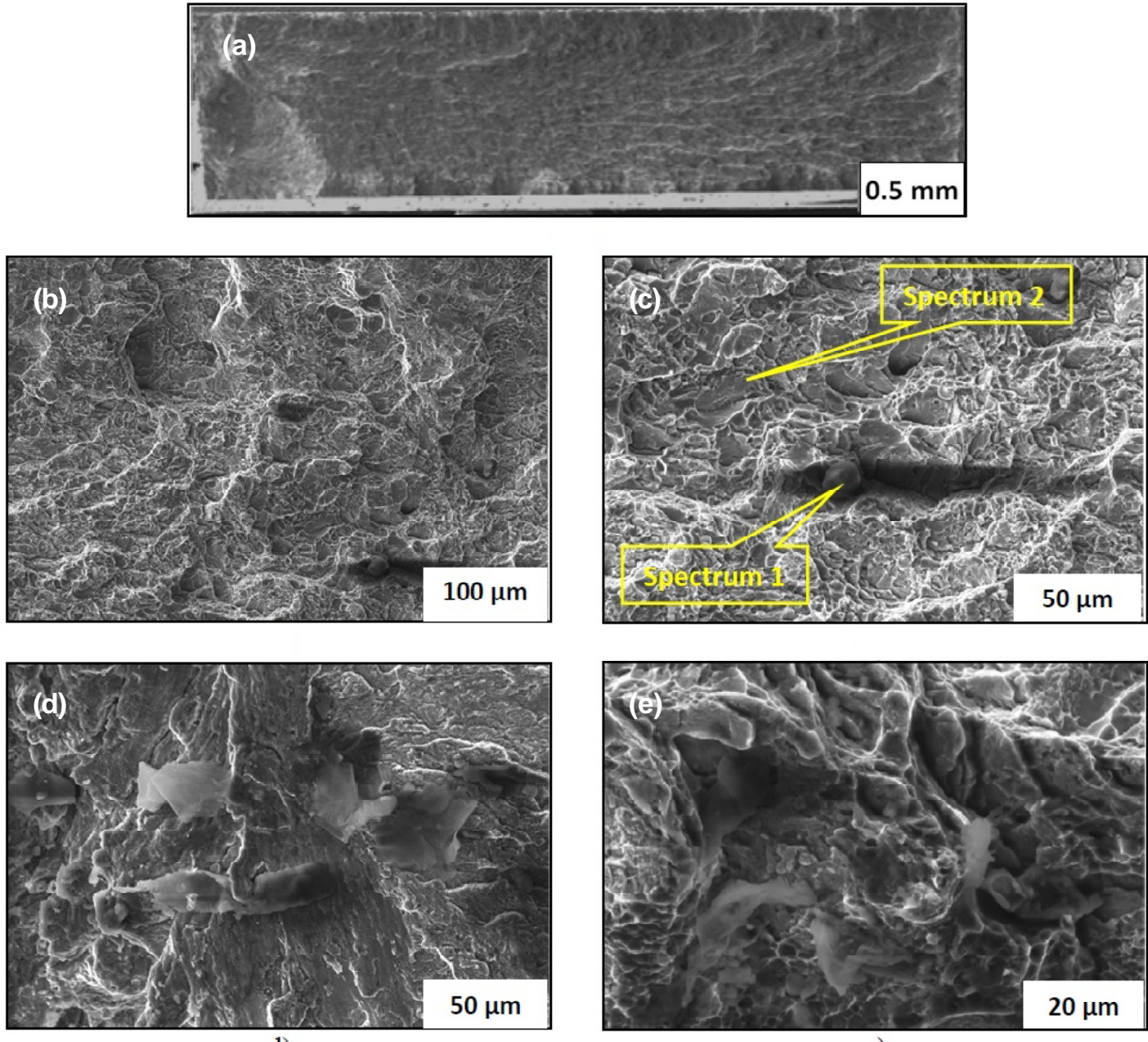

Fig. 7. General view of fractured specimen (a) and details of fractured zone for (b, c, d, e) for nanostructured LFW titanium after tensile testing. In (c) there are shown points for EDS analysis. 
Table 2. Chemical composition of the points shown in Fig. 7c (wt. \%).

\begin{tabular}{llllllllll}
\hline Points & C & Fe & H & N & O & Si & $\begin{array}{l}\text { Other } \\
\text { impurities }\end{array}$ & Ti \\
\hline Spectrum 1 & 66.7 & - & - & - & 22.7 & - & 1.0 & 9.6 \\
Spectrum 2 & 15.1 & - & - & - & 18.4 & - & - & 66.5 \\
\hline
\end{tabular}

surface of nanostructured LFW titanium. Apparently fracture of linear friction welded ECAP titanium is more brittle comparing to coarse-grained LFW specimen (Fig. 6). From Fig. 7a one may deduce that fracture onsets in non-homogeneous mode from

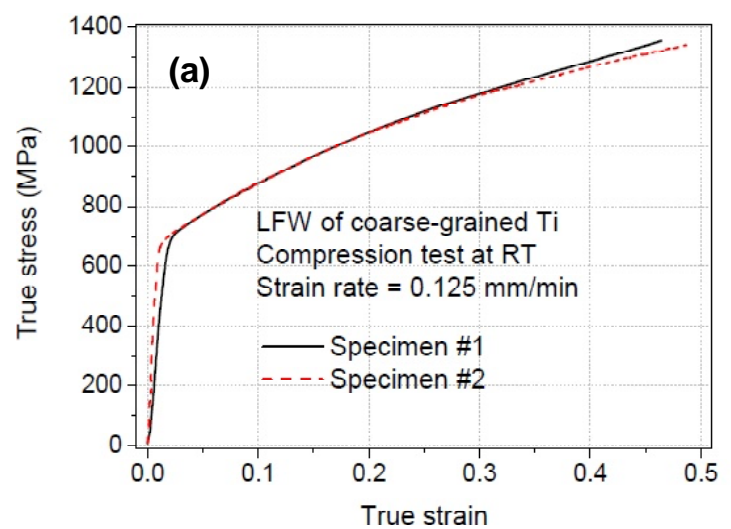

left-down corner and propagates through the whole cross section. Details of the fracture surface (Figs. $7 \mathrm{~b}-7 \mathrm{e}$ ) clearly reveal quasi-brittle type of rupture. Fig. $7 \mathrm{c}$ demonstrates obvious crack development around the particle. Chemical analysis of the particle and

Fig. 8. Engineering stress-strain curves for coarse-grained and nanostructured LFW samples of titanium tested in compression.
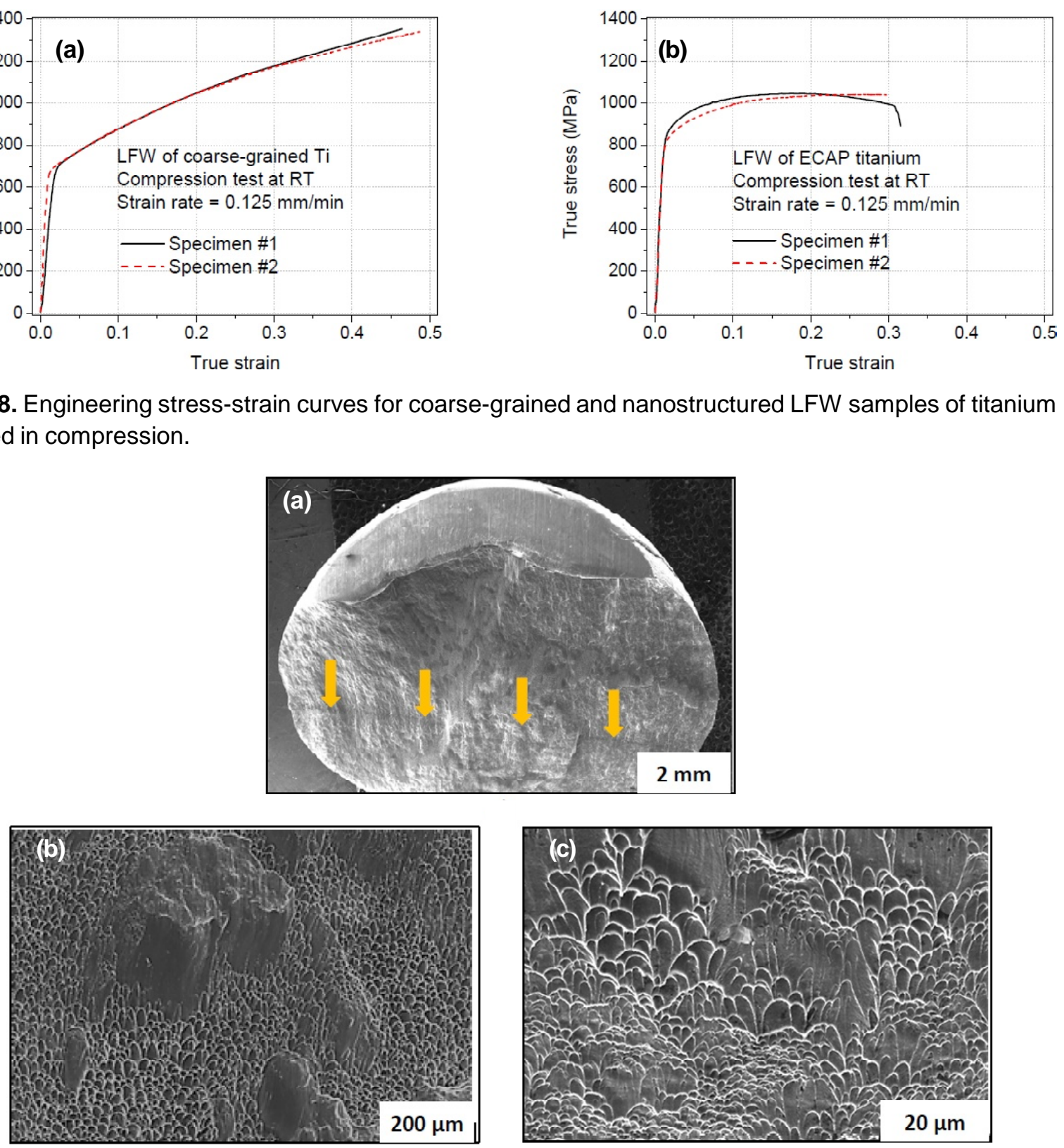

Fig. 9. General view of fractured specimen (a) and details of fractured zone for (b, c) for nanostructured LFW titanium after compression test. 
chemical composition of the metal outside of the crack are summarized in Table 2. Apparently the particle is a titanium carbide.

Compression testing: Fig. 8 exhibits stress-strain curves of compression test for coarse-grained and nanostructured titanium after linear friction welding. LFW coarse-grained titanium shows prominent strain hardening region till end of the test. Specimens were not fractured. Linear friction welded ECAP titanium shows rather typical stress-strain behavior and specimens were fractured at strain about 0.34 . Fracture surface of LFW nanostructured titanium is shown in Fig. 9. Low magnification view (Fig. 9a) indicates that the specimen was ruptured through complete longitudinal section including welding zone as indicated by arrows. Higher magnification of the fracture surface near the welding zone reveals some interesting details in the microstructure: large grains are incorporated into a matrix of small grains. The microstructure indicates two types of fracture: brittle mode connected to large grains and ductile type of small grain matrix.

\section{CONCLUDING REMARKS}

Linear friction welding was performed in two types of Ti samples: coarse-grained and nanostructured processed by ECAP. Microhardness measurements, tensile and compression tests of welded specimens with two different microstructures allow deriving the following conclusions:

- Tensile properties of both coarse-grained and nanostructured samples are identical and they reflect the mechanical behavior of the heat affected zone with predominantly ductile mode of fracture.

- Compression test demonstrated significant differences in properties of both coarse-grained and nanostructured titanium samples subjected to LFW: coarse-grained specimen possesses extended region of strain hardening while nanostructured specimen shows typical strain-stress behavior displaying fracture at strain of about 0.34. Transition area between welding zone and heat affected zone showed mixing type of fracture: brittle mode related to coarse grains and ductile mode related to fine grains.

\section{ACKNOWLEDGEMENTS}

A.P. Zhilyaev and G.I. Raab gratefully acknowledge financial support from the Ministry of Science and Higher Education of the Russian Federation (Grant 14.Z50.31.0043).

\section{REFERENCES}

[1] A.R. McAndrew, P.A. Colegrove, C. Bühr, B.C.D. Flipo and A. Vairis // Prog. Mater. Sci. 92 (2018) 225.

[2] A. Vairis and M. Frost // Wear 217 (1998) 117.

[3] A. Vairis and M.Frost // Mater. Sci. Eng. A 271 (1999) 477

[4] P.E. Denney and E.A. Metzbower // Weld J. 68 (1989) 342s.

[5] P.S. Liu, W.A. Baeslack III and J. Hurley // Weld. J. 73 (1994) 175.

[6] W.A. Baeslack III // J. Mater. Sci. Let. 1 (1982) 229.

[7] P. Wanjara and M. Jahazi // Metall Mater Trans A 36 (2005) 2149.

[8] M.V. Karavaeva, S.K. Kiseleva, V.M. Bychkov, A.Y. Medvedev, A.V. Supov, F.F. Musin, I.V. Alexandrov and V.V. Latysh // Let. on Mater. 2 (2012) 40.

[9] T.J. Ma and W.-Y. S.Y. Li // Mater Des 30 (2009) 2128.

[10] G.R. Suleimanova, R.R. Kabirov, M.V. Karavaeva, Yu.A. Ershova and A.P. Zhilyaev // Rus. Phys. J. 58 (2015) 815.

[11] R.Z. Valiev, A.P. Zhilyaev and T.G. Langdon, Bulk Nanostructured Materials: Fundamentals and Applications (Wiley, Hoboken, NJ, USA, 2014).

[12] R. Boyer, G. Welsch and E.W. Collings, Materials Properties Handbook: Titanium Alloys (ASM Intl, Metals Park, OH, 1994).

[13] A.M. Husnullin and R.M. Kashaev // Let. on Mater. 6 (2016) 227.

[14] D.V. Gunderov, A.V. Polyakov, I.P. Semenova, G.I. Raab, A.A. Churakova, E.I. Gimaltdinova, I. Sabirov, J. Segurado, V.D. Sitdikov, I.V. Alexandrov, N.A. Enikeev and R.Z. Valiev // Mater. Sci. Eng. A 562 (2013) 128. 